Kong. Res. J. 4(2): 127-129, 2017

ISSN 2349-2694

Kongunadu Arts and Science College, Coimbatore.

\title{
SCREENING OF ANTIMICROBIAL ACTIVITY IN PENTATROPIS MICROPHYLLA (ROTH) WIGHT (APOCYNACEAE)
}

\author{
Prema, $\mathbf{R}^{1 *}$.and J. Thambiraj ${ }^{2}$ \\ ${ }^{1}$ Department of Botany, Arulmigu Palaniandavar Arts College for Women, Palani. \\ ${ }^{2} \mathrm{PG}$ and Research Department of Botany, The Madura College (Autonomous), Madurai. \\ *E.mail: rprema22@gmail.com
}

\begin{abstract}
The stem bark extracts of the medicinal plant species, Pentatropis microphylla Roth Wight by using three alcoholic solvents viz; petroleum ether, ethyl acetate and methanol were tested against four human pathogenic bacteria viz., Bacillus subtilis, B. thuriengensis, Klebsiella pneumoniae and Escherichia coli and four human pathogenic fungi viz., Aspergillus niger, A. flavus, A.baumannii and Fusarium oxysporum for assessing the antimicrobial properties by adapting disc diffusion method. The results of the study revealed that all extracts showed varied degree of antimicrobial activity against the tested pathogens. However, the ethyl acetate extracts exhibited higher inhibition zone $(17.23 \mathrm{~mm})$ against the bacterium, Klebsiella pneumoniae and the fungus, Aspergillus niger $(19.63 \mathrm{~mm}$ ). Therefore the result strengthens the existing traditional usage of the plant for the therapeutic use.
\end{abstract}

Keywords: Medicinal plant, Pentatropis microphylla, Disc diffusion, Microorganisms.

\section{INTRODUCTION}

In Ayurvedic Medicine, there are numerous herbs which have been used historically for treating a large variety of ailments. Medicinal plants are the richest bio-resource of drugs of traditional systems of medicine, modern medicines, nutraceuticals, food supplements, folk medicines, pharmaceutical intermediates and chemical entities for synthetic drugs (Suparna et al., 2014). Spices have been used for not only flavor and aroma of the foods but also to provide antimicrobial properties (Nanasombat et al., 2002). Spices may contribute piquancy of foods and beverages (Praveen et al., 2006). In addition to these spices are some of the most commonly used natural antimicrobial agents in foods. Some of the natural compounds found in various spices possess antimicrobial compounds. Pentatropis microphylla belongs to the family, Apocynaceae is one such medicinal plant used in traditional system of medicine in Anthiyur forests of Erode district of Tamil Nadu, India. It is a climber, mostly distributed in undisturbed deciduous forest margins of peninsular India, Srilanka and Pakistan (Gibbs et al., 1987). The plant has the properties of antifungal, antiseptic and keratolytic. It is used in the treatment of skin problems also. The plant contains octacosanol, alpha-amyrin, friedelin and betasitosterol and an appreciable amount of salicyclic acid has also been isolated from this plant. It also reported to have a cardiac glycoside (Fatope, 1995). The plant is mentioned as cooling and alternative properties and useful in gonorrhea. It is used in constipation, colic and diarrhoea. It is used traditionally in acidity and fever. However, no published works are available for the antimicrobial property of stem bark of this plant. Hence in the present study, an attempt has been made to focus the plant in this angle and hence to assess its therapeutic potency.

\section{MATERIALS AND METHODS}

\subsection{Plant material}

Fresh stem barks were collected from the population of $P$. microphylla present in the Anthiyur forests of Erode district and washed under running tap water, air dried and then homogenized to fine powder and stored in air tight bottles.

\subsection{Preparation of extracts}

$250 \mathrm{~g}$ air-dried stem bark powder was subjected to $250 \mathrm{ml}$ of methanol in soxhlet extraction for 8 hours $\left(50-85^{\circ} \mathrm{C}\right)$. The extracts were concentrated to dryness in a flask evaporator under reduced pressure and controlled temperature $\left(50-60^{\circ} \mathrm{C}\right)$ to yield crude residue, which was then stored in refrigerator. To obtain petroleum ether and ethyl acetate extracts, the same method as used to obtain methanol extract was adopted.

\subsection{Media used}

Freshly prepared nutrient agar medium and PDA medium were used for the culture of bacteria and fungi respectively. 


\subsection{Microorganisms}

In vitro antimicrobial activity was examined for the chemical extracts of stem bark of the study plant, against four bacterial species which include the gram positive strains viz., Bacillus subtilis, $B$. thuriengensis and gram negative strains viz., Klebsiella pneumonia and Escherichia coli and four fungal species viz., Aspergillus niger, A. flavus, $A$. baumannii, Fusarium oxysporum. All these microorganisms were obtained from the Department of Microbiology, Hindustan College of Arts and Science, Coimbatore. All the microorganisms were maintained at $4{ }^{\circ} \mathrm{C}$ on nutrient agar slants (for bacteria) and PDA slants (for fungi) until furtheruse.

\subsection{Antimicrobial assay}

The alcoholic extracts were tested for their effect against the growth of pathogenic bacteria and fungi by disc diffusion method (Bauer et al., 1966). Both the organisms, bacteria and fungi tested were inoculated into nutrient agar and PDA media respectively. After an incubation period of $24 \mathrm{hrs}$ at a temperature of $35^{\circ} \mathrm{C}$, three or four colonies isolated from these media were inoculated into $4 \mathrm{ml}$ of nutrient broth and incubated for $2 \mathrm{hrs}$ at $35^{\circ} \mathrm{C}$. The cultures were adjusted with sterile saline solution to obtain turbidity. Petri dishes containing MullerHinton agar medium and PDA medium were streaked with these microbial suspensions of bacteria and fungi respectively. Disks of $6 \mathrm{~mm}$ diameter were impregnated with the extracts of petroleum ether, methanol and ethyl acetate separately. Tetracycline is used as positive control.
After equilibrium at $4^{\circ} \mathrm{C}$, the plates were incubated overnight at $37^{\circ} \mathrm{C}$ and the diameter of any resulting zones of inhibition was measured. Each experiment was repeated at least three times.

\section{RESULTS AND DISCUSSION}

The antibacterial activity of the all the alcoholic stem bark extracts of the study species, Pentatropis microphylla generally showed inhibitory activity against the growth of Bacillus subtilis, $B$. thuringiensis and Klebsiella pneumoniae. However, towards Escherichia coli, all these extracts showed activity with less pronounced manner (Table 1). Further, the ethyl acetate extract has determined to have highest inhibitory activity $(17.23 \mathrm{~mm}$ diameter inhibitory zone) against the bacterium, Klebsiella pneumoniae (gram negative) and followed by the methanol extract showed the higher inhibitory activity against the bacterium, Escherichia coli (14.17mm diameter inhibitory zone). It indicates the presence of effective active principle compounds in the ethyl acetate and methanol extracts of stem part of Pentatropis microphylla to suppress bacterial activity. It has been observed further that the ethyl acetate extracts showed significantly higher inhibitory activity against the colonial growth of Klebsiella pneumoniae than that of the commercially available antibiotic, tetracycline. This fact shows the higher therapeutic potential of ethyl acetate extract of the study species. The petroleum ether extract has comparatively less activity against the tested pathogens. It may be attributed to the presence of respective active compounds with insufficient quantities in this crude extract.

Table 1. Antibacterial activity of certain alcoholic stem bark extracts of the species, Pentatropis microphylla.

\begin{tabular}{lllll}
\hline \multirow{2}{*}{ Plant extract } & \multicolumn{4}{c}{ Diameter of zone inhibition (mm) } \\
\cline { 2 - 5 } & \multicolumn{2}{c}{ Gram positive bacteria } & \multicolumn{2}{c}{ Gram negative bacteria } \\
\cline { 2 - 5 } & $20.77 \pm 0.20$ & $18.06 \pm 0.56$ & $11.33 \pm 0.42$ & $16.12 \pm 0.61$ \\
pneumoniae & Escherichia coli \\
\hline Standard* & $11.87 \pm 0.15$ & $10.16 \pm 0.57$ & $9.16 \pm 0.37$ & - \\
Petroleum ether & $11.03 \pm 0.61$ & $17.23 \pm 0.58$ & $14.16 \pm 0.66$ \\
Ethyl acetate & $12.13 \pm 0.61$ & 11.03 & $13.73 \pm 0.75$ & $8.06 \pm 0.30$ \\
Methanol & $11.16 \pm 0.47$ & $14.17 \pm 0.60$ & 130 & \\
\hline
\end{tabular}

* Tetracycline

Table 2. Antifungal activity of certain alcoholic stem bark extracts of the species, Pentatropis microphylla.

\begin{tabular}{lllll}
\hline \multirow{2}{*}{ Plant extract } & \multicolumn{3}{c}{ Diameter of zone inhibition(mm) } \\
\cline { 2 - 5 } & Aspergillus niger & \multicolumn{1}{c}{ A. flavus } & A. baumanii & Fusarium oxysporum \\
\hline Standard* & $24.67 \pm 0.48$ & $23.17 \pm 0.67$ & $26.73 \pm 0.67$ & $30.73 \pm 0.67$ \\
Petroleum ether & - & $10.24 \pm 0.78$ & $12.73 \pm 0.66$ & - \\
Ethyl acetate & $19.63 \pm 0.53$ & $18.77 \pm 0.71$ & $19.45 \pm 0.71$ & $15.67 \pm 0.59$ \\
Methanol & $10.73 \pm 0.54$ & $11.73 \pm 0.70$ & $14.63 \pm 0.65$ & $12.17 \pm 0.38$ \\
\hline
\end{tabular}

\footnotetext{
* Tetracycline
} 
The antifungal activity of various alcoholic stem bark extracts of the study species, Pentatropis microphylla against the four studied fungal species is given in Table 2. The results of the study report that the ethyl acetate extract has the highest inhibitory activity (19.63 mm diameter inhibitory zone) against the fungus, Aspergillus niger. The methanol extract showed considerable effect to all the tested fungal pathogens. The petroleum ether extract was also found to be better with respect to inhibitory function only against the two fungal species, Aspergillus flavus, A. baumannii. Significantly higher inhibitory activity of ethyl acetate extract is nearly to the commercially available antibiotic tetracycline against the fungus, Aspergillus niger observed shows the superior healingness of stem bark of $P$. microphylla.

The results of present investigation clearly indicated the antibacterial and antifungal efficacy of the study species Pentatropis microphylla stem bark extracts. This activities may probably due to the presence of bioactive compounds like flavonoids (Tsuchiya et al., 1996), phenolics and polyphenolics (Mason and Wasserman, 1987), tannins (Ya et al., 1988), terpenoids (Scortichini and Pia Rossi, 1991), sesquiterpenes and glycosides (Varshney et al., 1996) are effective antimicrobial substances against a wide range of microorganisms.

This fact indicats the existence of strong antifungal activity of leaf part of the study species, $A$. caesia and hence its effective healing property against the infectious diseases. Proper isolation and purification of active compounds by using ethyl acetate solvent would ensure the therapeutic value of this medicinal plant when it will be used commercially.

\section{REFERENCES}

Bauer, R.W., M.D.K. Kirby, J.C. Sherris and M. Turek, (1966). Antibiotic susceptibility testing by standard single disc diffusion method. Am. J. Clin. Pathol. 45: 493-496.

Fatope., M.O., (1995). Phytocompounds: Their bioassay and diversity. Discov. Innov. 7: 229236.
Gibbs Russell, G.E., W.G.M. Welman, E. Retief, K.L. Immelman, G. Germishuizen, B.J. Pienaar, M. Van Wyk and A. Nicholas, (1987). List of species of southern African plants. Memoirs of the Botanical Survey of South Africa 2(1-2) 1152(pt. 1), 1-270(pt. 2).

Mason, T.L and B.P. Wasserman, (1987). Inactivation of red beet betaglucan synthase by native and oxidized phenolic compounds. Phytochem. 26: 2197-2202.

Nanasombat, S., V. Prasertsin, K. Graisin, H. Shain and B. Thanaboripat, (2002). Efficacy of $\mathrm{New}$ Enzyme- Linked Immunosorbent Assay for Rapid Detection of Salmonella in Foods. Gov. Pharmaceu. Org. Report Bangkok. 51: 53- 57.

Perveen, T. and M.A.C. Nazia, (2006). Bactericidal Activity of Black Pepper, Aniseed and Coriander against oral isolates. Pak. J. Pharmaceu. Sci. 19(3): 214-218.

Scortichini, M. and M.P. Pia Rossi, (1991). Preliminary in vitro evaluation of the antimicrobial activity of terpenes and terpenoids towards Erwinia amylovora (Burrill) Winslow et al. J. Appl. Bacteriol. 71: 109-112.

Suparna, D., P. Asmita and P. Shinde, (2014). Study of antioxidant and antimicrobial activities of Andrographis paniculata. Asian J. Pl. Sci. Res. 4(2):31-41.

Tsuchiya, H., M. Sato, T. Miyazaki, S. Fujiwara, S. Tanigaki, M. Ohyama, T. Tanaka and M. Iinuma, (1996). Comparative study on the antibacterial activity of phytochemical flavanones against methicillin-resistant Staphylococcus aureus. J. Ethnopharmacol 50: 27-34.

Varshney, I., P. Sharma and S.C. Saponins, (1996). Sapogenins: part XXXII. Studies on Trigonella foenum-graecum Linn. seeds. J. Chem .Soc. 43: 564-567.

Ya, C., S.H. Gaffney, T.H. Lilley, E. Haslam, (1988). Carbohydrate polyphenol complexation. In: Chemistry and significance of condensed tannins. Hemingway R.W and J.J. Karchesy (Eds.), Plenum Press, New York. pp. 553. 